\title{
Hyper-Elitism in Writing Literary Criticisms: Theories and References
}

Syed Mahmudur Rahman*

Senior Lecturer, Department of English, East West University, A/2 Jahurul Islam Avenue, Aftabnagar, Dhaka 1212, Bangladesh

Corresponding Author: Syed Mahmudur Rahman, E-mail: smrahman.ewu@gmail.com

\section{ARTICLE INFO}

Article history

Received: August 05, 2018

Accepted: October 20, 2018

Published: December 28, 2018

Volume: 9 Issue: 6

Advance access: November 2018

Conflicts of interest: None

Funding: None

\author{
Key words: \\ Literary Criticism, \\ Reader-friendliness, \\ Standard, \\ References, \\ Critics, \\ Literary Audience, \\ Elitist/Elitism
}

\begin{abstract}
Current day literary criticisms written in world englishes often seem to be a little hard to comprehend for readers because of critics' tendency to use too much decorative language with too many theoretical views, jargons, and references of different sorts just to stick to an assumed standard of scholarly writing. This paper, based on a generalized study though, considers that assumed standard hyper elitist, which is affecting the easy entrance of a considerable portion of literary audience into the literary realm where the popularity in the form of reader-friendliness and comprehensibility of literary criticisms are compromised, and thoughts of some creditable thinkers remain unnoticed only because those promising thoughts apparently fail to be expressed in that supposed standard of language. Keeping the purpose of literary criticisms in mind, this paper places forth a seemingly valid question whether this sophisticated way of expressing is really mandatory or not, as the word 'standard' itself is subjected to be modified when needed, and the postmodern approach to the literary regime really tends to unsettle the frame of any standardization and deny the distinctions between 'high' and 'low'. Thus, speculated implications of the paper included that the accessibility of greater number of audience into the arena of literary criticisms might be more liberally considered by established but elitist critics, while the stress of synthesized elitism in writing criticisms might also be mitigated for neophytes among critics.
\end{abstract}

\section{HYPER-ELITISM IN WRITING LITERARY CRITICISMS: AN OVERTURE}

The current day practice of writing literary criticism, considering the writings only in englishes, seems to carry the tendency of using elitist language with lofty expressions, rhetorical devices, and frequent literary and theoretical references, making articles fairly hard to comprehend through a friendly reading at once. Critics, usually the scholars of the literary realm, have their own sophisticated ways of depicting their thoughts and ideas. Issues and ideas themselves are sometimes complex, thus, not easy to be understood; while lofty expressions, the metachaotic ones, are actually adding on to readers' difficulty in terms of understanding. And, young and promising scholars seem to follow renowned scholars' trend as youngsters do not really want to be called 'childish' as far as the writing standard is concerned. Because of the trend, some are trying to make it a habit to express things in a rather complex manner while it is an intrinsic tendency for some of the writers. But, there are a few who are toiling at times, really tiring to achieve that sophisticated complexity of expression in order to attain that scholarly 'standard' set and practiced by elitist critics. Now, keeping the purpose of writing literary criticisms in mind, it is a val- id question to be placed whether this elitist and sometimes jargoned way of expressing thoughts with frequent literary and theoretical references, even when it is not that necessary to carry the intended message, is really necessary or not. To place an answer to the question, considerable issues include better comprehensibility and reader-friendliness, spreading the thoughts to the general mass crossing that 'elitist' and 'modern' standard of literary criticisms, and approaching the literary realm from the view point of transcending the frame of stereotypical 'standard'.

\section{THE EXTENT AND FUNCTION OF LITERARY CRITICISM}

Before getting into the focal core of the discussion of this paper, the part of the title, "Literary Criticisms" may need a defining frame. Generally, the word 'literature' denotes "writings that are valued as works of art, especially fiction, drama, and poetry in contrast with technical books and newspaper, magazines, etcetera" ("Literature"). With the word 'literature', a commonly accepted notion is to refer to creative writings where imagination has no limit from authors' points of view; and contents are never questioned 
from the perspective of being fact though creative literature very often follows, imitates, or replicates facts, sometimes even represents facts through different literary techniques, devices, and 'amulets'. And in the postmodern era, forms and genres of literature are also enjoying a widespread range of varieties including some that are even a bizarre and/or shocking at times. In the literary realm, the variety of genres also includes orature, songs, audios, and audio-visuals. Now, 'literary criticism' is also a part of the literature ring but not really the part of creative literature. Rather, a piece of literary criticism, as this paper considers, is the type of critical writing, mainly in prose, that deals with the conception, composition, promotion, and/or consumption of creative literature. Thoughts and ideas along with the issues raised and discussed in literary criticisms require creative thinking, but these are not parts of creative literature because these are not primary fictions; these are secondary writings based on issues involved in creative pieces; and unlike creative pieces, critics' discussions should always be logically framed and justified.

Now, the purpose of literary criticism is to open multi-angular windows to approach to the world of literature through them, and these approaches act with prismatic principles of dispersing any singular intake into multi-coloured interpretations. Thus, criticisms are supporting tools to make creative literary pieces better conceptualised and composed by authors and better promoted to and consumed by the literary audience.

\section{LANGUAGE STANDARD IN LITERARY CRITICISM}

With having the aforementioned idea of literary criticism, let the focus be shifted to the 'standard of language' of the literary realm with a special light spotted on the language standard of literary criticisms. The realm of literature contains multifarious varieties in terms of forms and genres, starting from ancient tablets and classical epics and tragedies to current day one-liners, or even careless graffities; though this is a different debate that whether the literary regime should have that much elasticity or liberal attitude or not, to incorporate those careless forms of writings available around to be called as 'literature', shedding off the 'modern' notion of 'elitism'. But even in well acknowledged forms and genres, the language has a wide range of varieties depending on different pieces, different writers of different times, topics, contents, contexts, themes, genres, and so forth. Thematically, creative literature is spacing in the 'absurds', having chaos deterministically existing in and carrying purposeful disorderliness. Creative literature has the scope of accommodating the most sophisticated version of language, letter by letter allusions, and hyper-whimsical encoding through appropriation and abrogation of the standard version of any language. At the same time, creative literature has the way open to space in the simplest of expressions with all the non-standard colloquial varieties, being deliberately unconscious about set standards and artistically denying all grammatical pins and norms. Poets of all literary ages have been enjoying ever so whimsical ways of experimentation through elegantly and eloquently ignoring grammatical pins like punctuation, capitalization, spelling, and so forth; while prose-writers have also been abrogating and appropriating their language according to their sweet wills. And in fact, no one seems to have question against, rather the experimentation with language has been an ever appreciated phenomenon; and this is because, deliberately crafted varieties in expression have always been carrying multi-coloured and multi-layered twists and significance that add on to the beauty of the rainbow shining against the widespread heavens of literature.

Whereas, literary criticism is one of the well accepted forms of writing in the literary arena; but as stated earlier, it is not regarded among creative pieces though critics have to employ lots of creative thinking and interpretative angles. This is like a defender scoring in a game of football. The defender is not called a striker even after striking goals. So, being a 'side' concern or by-product of creative literature, literary criticisms seem to enjoy lesser freedom than creative pieces usually do in terms of variety of standards in a language. Literary criticism always remains a field where critics must stick to the 'standard' version of language pinned and framed by grammatical norms as this is, perhaps, the most 'formal' field of writing as far as different literary writings are concerned. There is no harm being the most formal and grammatically neat in writing; but what is being observed that, with having the freedom of experimenting with expressions, creative literary pieces are coming closer to the general mass, incorporating varieties of expressions from the daily-living. This step towards populism from elitism is a prominent feature in postmodern literary culture; even in fictions of earlier ages, there are several instances of using the colloquial varieties of language. On the contrary, literary criticisms, being categorized in the most formal branch of literary writing, only aspire the elite standard, resulting in getting increasingly critical to be decoded at times. Literary critics are holding onto the typically elite standard, and this elitism is devaluing the so claimed 'informal' thus 'inferior' versions of expression. Moreover, that inward elitism of critics is adding on to the difficulty in understanding of the general mass, of some of the students and rising practitioners of literature, even of a few of the experts of the field. It is not the case that some, majority, or all of the criticisms are not at all understandable or very hard to understand, but lack of reader-friendliness is certainly an issue prevailing there.

\section{CRITICS EYING TO HOLD ON TO THE 'STANDARD'}

The ongoing trend of writing literary criticism maintaining an elevated standard with the use of highly sophisticated and stylistic expressions seems to become already accepted and, more objectionably, stereotyped. As it is stated earlier, critics, especially the rising ones, are very much concerned about their 'standard' of language as otherwise, they run the risk of being called 'childish' in case of expressing their thoughts and/or the risk of not being considered among the posh group of scholars/critics. Again, many are heavily focusing on language or expressions just to assert their 
linguistic prowess where, once again, the target of being branded among renowned critics subconsciously prevails. It also seems to provide a psychological pleasure if something is expressed, either tediously or elegantly, in a rather intricately crafted manner. But, in search of that highness in expressing thoughts and ideas, critics often seem to synthesize their language to such an extent where they have to compromise with the comprehensibility of their writings and the reader-friendliness of the mass audience. Critics often forget what George Orwell remarks - "Language is a natural growth and not an instrument which we shape for our own purposes" (127).

\section{LITERARY CRITICISM: THE AUDIENCE'S PERSPECTIVE}

Now, why has reader-friendliness in literary criticism been being repeatedly mentioned and focused in this paper- is a logical query. To get to the answer of this question, the purpose of writing literary criticism should be taken into consideration with due seriousness. As stated earlier, literary criticisms are to open multi-angled windows to approach the literary world through, to create wide-ranging platform for creative writers, and also to provide better understanding of creative literary pieces to the literary audience. Now, keeping those purposes into mind, the range of the literary audience is a crucial consideration. In this postmodern era the world of literature is no more an elitist regime. Literature is now for all, and more importantly, perhaps, from all as well. The rather idiosyncratic lines between 'high' and 'low' literature are shadow lines now a day. And therefore, the term 'literary audience' refers, perhaps, to the masses. An archetypal belief prevails in the arena of literary criticism that papers for publication are meant to be read by scholars and experts of this field, which is valid for initial stages of the publication process like expert review or editing; but, when an article gets published, it should not consider only scholars as its audience-body. If the article can transcend the elitist arena of scholars to reach the masses as literary audience, it is beneficial for the entire world of literature and its growing popularity. But, when articles apparently cannot meet up the 'standard' highness in expression, not necessarily in thoughts though, they cannot pass through the elitist reviewing by experts. There was a time when popular culture was considered as 'low' culture by elitists, and the same was applicable for the field of literature. But now, populism in culture, including literature, is a celebrated phenomenon in postmodern idea of culture. Popularity really matters these days. But, that prevailing sense of scholastic elitism in literary criticism has a line of clash with the idea of populism. Though literature becomes a field for the mass-interest, literary criticism still remains a field only for 'scholars' to have access in. Here comes a simple logic that if literature is for all, the arena of literary criticism should also be easily accessible for all. Reader-friendliness in literary criticism with the use of simple wording and expressions can function as a positive catalyst to widen that access, while the elitist tendency of using sophisticated and complex expressions works the opposite way.

\section{LITERARY CRITICISM: DENOTATION OF CRITICS}

For other branches of knowledge, critics are experts or specialists. But, as literature is commonly believed to be the reflection of life on a mass scale, the literary audience is the masses. And, as literary criticism is also about the consumption of creative literary pieces, can the idea of being a literary critic be liberalized to a wider extent to slot in some thoughts of the masses who are out of the panel of scholars excessively obsessed with elitism? To consider this issue, it is to be checked that what should be the parameters through which a criticism should be evaluated. Is it the critic, his or her scholastic background or career achievement, his or her level of sophistication in using language, or his or her attitude and/or fluent reaction towards any literary concern? If it is taken that criticisms should come from only those who have fame as critics, or who can express their thoughts with the touch of sophistication so that the language matches with the elite standard of literary criticisms, it may be unwise; because in that case, the attitude, opinion, and/or reaction of a large percentage of the literary audience may remain unnoticed. There can be many creditable thinkers in the literary audience who are really creative and who are able to contribute to the field of literary criticisms with many constructive thoughts and ideas. If the field of literature is for all, the mass level criticism is also to be acknowledged; and only because someone cannot express his or her thoughts in 'standard' language, his or her opinions, reactions, or criticisms should not be undermined or branded as 'low'.

\section{THEORIES AND REFERENCES IN LITERARY CRITICISMS}

In terms of applying theories in a critical literary non-fiction prose, an inward exigency seems to prevail; and, a denial of that urge, no matter how much otherwise constructively it is accomplished, runs the risk of being undermined by the elitist regime of scholars.

Another typical trend of critics is to use references in the form of quoting, dropping big names, using special coinages, or giving some passing references. These references support and/or strengthen claims or thesis of any critical discussion. Sometimes, references also help readers' better understanding of a text. But, a few of the critics use references because they think that this is necessary for any literary criticism to have a good number of references; otherwise, the criticism will not be regarded as a good one. Because of that thought, writings of some critics often become needlessly stuffed with frequent references.

Now the question is, is this practice of using theoretical or literary references acceptable, good, or 'a must'. As stated earlier, references can assist a critic to have supportive back up; at the same time, they can assist a reader to have better understanding, perhaps, through intertextuality. Thus, using references is certainly all right, even, a good practice. But, as overdoing everything is problematic, same goes with the practice of using references. If a critic has the tendency of using too many references, it may interrupt the flow of the 
original discussion, it may suggest a critic's lack of self confidence as the writing will seem to be too much dependent on outside support to establish the concerned issue, or it may even imply the lack of original or primary thoughts from the critic's part. And, it gets even worse when the practice of using references in writing a literary criticism is considered 'a must' by some of the critics. These critics seem to carry a belief that without a considerable number of references, both literary and theoretical, a criticism cannot be a 'standard' one. This sort of standardization is indeed questionable as it indirectly dispirits the novel thinking and devalues the originality of any critic.

From another view point to this argument, it can be said that, everything one knows has a source; and thus, whatever someone expresses is somehow plagiarized. So, as we cannot really copyright the entire domain of knowledge, aspiring (from writers' point of view) or expecting (from readers' point of view) too much support from quoted materials is not also quite legitimate. Right at this point, a Terence from second century BC can be quoted as he said, "There's nothing to say that hasn't been said before" (qtd in Shields, 7). But, even if this reference to a Terence from second century BC is not used here, does it really weaken the appeal of the thought which is plainly self-affirmative?

Moreover, references are often confined to a cluster of big names which are already enjoying a privileged platform in the literary arena. But, it is always better to assert oneself as the first ' $Y$ ' than as the second ' $X$ ' if the first ' $X$ ' already exists. Critics should not always seek back up from big names because a truly pioneering idea does not necessarily need a heavy back up. Rather, it would be something praiseworthy if a critic has the confidence that his/her idea can singlehandedly influence others to accept/follow the idea.

Besides, there is another belief in many of the critics in terms using passing references that matches with the tendency of deliberately using complex and jargoned expressions in writing in order to be branded among the elite panel of literary scholars. There, critics show the tendency of using too many passing references in writing that may give the taste of literary literacy to such readers who can recognize the inter-textual connection of those references, but at the same time, this practice will have no impact on those readers who are not familiar with the reference/s. Critics may not bother about the little literate audience's failure to decode the taste, but if too many passing references are used, it may sometimes affect the core meaning to be conveyed to the audience. So, it is 'a modest proposal' to critics to maintain a balance between the use of passing literary references in order to decorate writings in literary criticisms and the objective of conveying the right message to readers. It is quite logical that creative writers use as many passing references as they wish because creative literary pieces are actually the places where writers have the full freedom of embellishment whereas the job of critics is to break into the decorative coding to infer possible meanings. Now, if critics become too ornamental to be understood, then general readers may get denied of the core essence of many literary concerns. A point may be noted here as the expression, 'a modest proposal', placed in a few sentences back, may stand as an example of passing literary reference. Now, those who can easily recognize this expression as the title of Jonathan Swift's hyperbolic satire, they can sense an additional touch here. But, even if someone is unaware of the connection of the reference, he or she will only miss the extra added touch but can easily understand the meaning of the sentence for the focal purpose of the discussion simply decoding the denotations of the words - 'modest' and 'proposal'. And thus, here the balance between the use of decorative reference and the conveyance of the message is not really affected.

\section{UNSETTLING THE 'STANDARD'}

In terms using elevated expressions or references, the assumed standard, perhaps, is leading critics to become difficult to be understood by readers; and at the same time, some promising thinkers are not getting easy entrance into the panel of literary critics as they are not that much up to the mark in terms of expressing their thoughts as far as the set standard is concerned. But the word 'standard' itself, of course, is not beyond question. What should be the standard, who should be authorised to set the standard, how long a set standard should prevail, or why should not the standard be modified if required - these are sensible questions not to be overlooked. Especially in this postmodern era, the word 'standard' is like a fluid phenomenon which can certainly be questioned, criticised, and also re-standardized when needed. So, to incorporate the mass criticism into the world of so called standard literary criticisms and to increase the comprehensibility of critics' writings, modification of the so far cherished standard is expected. Any stereotyping in terms of the highness of language or number of references should not be in operation while measuring the worth of a piece of literary criticism.

The 'chaos' in text is a creative phenomenon; and, chaos theory rather praises the metachaotic approach of creative writers as chaos theory explains that a creative piece having multi-fold treasure of interpretations takes a long time to unfold or unriddle. Thus, the piece enjoys a long lasting appeal; and the longer that appeal exists, longer the piece rounds into the literary orbit and greater the piece becomes. But, as the purpose of a literary criticism is to decode the chaos for the readers, the criticism itself being metachaotic like creative pieces may not always be functioning for the right purpose.

A point is to be noted here that scholars study critical matters, but when it comes to share the outcome with the masses, scholars simplify complex issues to match the general understanding; whereas, the literary critics seem to even intensify complexities, at times, rather unnecessarily, just for the sake of sticking to that assumed standard.

\section{A FEW CLOSING WORDS}

The use of 'high' language synthesized with elitist expressions in literary criticisms is not something being proscribed here in this argument. Those who are instinctively doing so, it is very much all right; but alongside, if they duly consider the issue of understanding of their audience and 
the reader-friendliness of their writings, the entire literary realm will get benefited. But, those who are toiling to attain that assumed standard and those who are having the belief that without maintaining that standard with elevated expressions, criticisms will not be highly regarded, they can certainly give a second thought to modify their belief by a little margin. While in case of using theoretical and literary references in literary criticisms, critics should have the ultimate free-will regarding when to refer, how to refer, who to refer, and how many times in a writing to refer. But, there should be a concern so that too many references, if not really needed, may not spoil the novelty of the critic. And after all, compromising with the reader-friendliness of writings and with readers' easy understanding just to stick to a supposed standard is something that this paper tries to put lights on and question. Because, considering writings in current day world englishes, it is evident that just to hold on to a set 'standard' and to brand themselves among high scholars, critics are often needlessly making their language too much elevated using some otherwise avoidable jargons and frequent references, which is actually affecting the comprehensibility and reader-friendliness of criticisms, resulting in producing some jargoned junk apparently very luring to be consumed but likely to create digestive malfunction in neurons of readers' brains.

\section{REFERENCES}

"Literature." Oxford Learner's Dictionaries, www.oxfordlearnersdictionaries.com/de inition/English/literature. Accessed 7 Aug. 2018

Orwell, George. "Politics and the English Language." The Essays, Journalism and Letters of George Orwell, ${ }^{\text {st }} \mathrm{ed}$, edited by Sonia Orwell and Ian Angos, Harcourt Brace Jova-novich, 1968, pp. 127-40.

Sheilds, David. Reality Hunger. Penguin Books, 2011. 